\title{
Desafios da coleta seletiva e a participação dos catadores de materiais recicláveis em Simão Dias, $\mathrm{SE}$, Brasil
}

\author{
Desafíos de la colecta selectiva y la participación de los \\ catadores de materiales reciclables en Simão Dias, SE, Brasil
}

\section{Challenges of selective collection and the participation of recyclable material catalysts in Simão Dias, SE, Brazil}

\author{
Ariane Siqueira de Oliveira \\ arianegeoufs@bol.com.br \\ Universidade Federal de Sergipe, UFS, Aracaju, SE \\ Anézia Maria Fonsêca Barbosa \\ aneziamaria.barbosa@gmail.com \\ Universidade Federal de Sergipe, UFS, Aracaju, SE \\ Maria do Socorro Ferreira da Silva \\ ms.ferreira.s@hotmail.com \\ Universidade Federal de Sergipe, UFS, Aracaju, SE
}

\begin{abstract}
Resumo: O artigo visa analisar os desafios que dificultam a coleta seletiva de resíduos sólidos em cidades de pequeno porte no Brasil. Foram entrevistados representantes do poder público, da cooperativa e catadores. A coleta seletiva feita pela cooperativa de catadores enfrenta dificuldades referentes à escassez de recursos financeiros, à falta de separação dos materiais recicláveis na fonte geradora, à vulnerabilidade social dos catadores, à dificuldade de gestão e engajamento dos cooperados. É relevante implementar projetos de Educação Ambiental para sensibilizar e estimular a participação do poder público, da comunidade e dos catadores, criar táticas para promover a inserção social, melhorar as condições de trabalho desse grupo e possibilitar a sustentabilidade da cooperativa.
\end{abstract}

Palavras-chave: Cooperativa, Gerenciamento de resíduos, Inclusão social, Sustentabilidade.

Resumen: El estudio busca analizar los desafíos que dificultan la recolección selectiva de residuos sólidos en pequeñas ciudades en Brasil. Se realizarón entrevistas con representantes del poder público, de la cooperativa y recolectores. La recolección selectiva hecha por la cooperativa de recolectores enfrenta dificultades referentes a la escasez de recursos financieros, la falta de separación de los materiales reciclables en la fuente generadora, la vulnerabilidad social de los recolectores, la dificuldad de gestión y compromiso de los parceros. Es importante implementar proyectos de Educación Ambiental para sensibilizar y estimular la participación del poder público, comunidad y recolectores, crear tácticas para promover la inserción social, mejorar las condiciones de trabajo de ese grupo y posibilitar la sostenibilidad de la cooperativa.

Palabras clave: Cooperativa, Gestión de residuos, Inclusión social, Sostenibilidad. 


\begin{abstract}
This paper aims to analyze the challenges that hinder the selective collection of solid waste in small cities in Brazil. We carried out interviews with representatives of the public power, the cooperative, and collectors. The selective collection made by the collectors' cooperative faces difficulties related to the scarcity of financial resources, the lack of separation of recyclable materials in its generating source, the collectors' social vulnerability, and the management and commitment difficulties of its members. It is important to implement Environmental Education projects to sensitize and stimulate the participation of public power, community and waste pickers, create tactics to promote social insertion and improve the working conditions of this group and make the cooperative sustainable.
\end{abstract}

Keywords: Cooperative, Waste Management, Social inclusion, Sustainability.

\title{
INTRODUÇÃO
}

Os problemas relacionados aos resíduos sólidos incidem em dificuldades de ordem social, econômica, de saúde e ambiental, especialmente pelas deficiências no planejamento urbano e na sensibilização da população, e nos demais segmentos da sociedade. A problemática que envolve o gerenciamento inadequado dos resíduos sólidos domiciliares tem sido comum nos municípios brasileiros, especialmente naqueles de pequeno porte.

O gerenciamento integrado de resíduos sólidos urbanos envolve etapas relacionadas à coleta regular, ao transporte, ao transbordo, ao tratamento, à destinação e à disposição final ambientalmente adequada dos rejeitos (BRASIL, 2010). Dessa forma, "Não cabe mais a denominação de lixo para aquilo que sobra no processo de produção ou de consumo. Demarcar estas diferenças é de suma importância" (FROTA et al., 2015, p. 132). Dentre essas etapas, destaca-se a coleta seletiva, forte alternativa para a recuperação de materiais (CAIXETA, 2005), considerada como a etapa prévia para que os resíduos sejam encaminhados para a reciclagem ${ }^{1}$.

No entanto, para resultados eficazes, a separação correta deve ser observada, uma vez que "Quando se misturam restos de alimentos com embalagens ou objetos inservíveis, eles se tornam, de fato, lixo, e seu destino será o lixão da cidade" (FROTA et al., 2015, p. 133). Nesse sentido, é necessário que a separação dos componentes que podem ser recuperados seja feita na própria fonte geradora (no domicílio, no comércio, na escola, ...) a partir de acondicionamento distinto para cada componente (MONTEIRO et al., 2001; CORTEZ, 2002).

Entretanto, realizar a coleta seletiva ainda está entre os desafios para municípios brasileiros, pois vem ocorrendo de modo insuficiente e insatisfatório (SCACABAROSSI; PÉRICO, 2014). Estima-se que, em 2017, havia 3.923 municípios com alguma iniciativa de coleta seletiva (ABRELPE, 2017), porém essas iniciativas nem sempre obtêm sucesso e geralmente não são dimensionadas para toda a área urbana. Ou ainda, como ressaltam Silva (2013) e Scacabarossi e Périco (2014), são realizadas apenas em Pontos de Entrega Voluntária (PEVs) e/ ou similares.

1 "[...] um conjunto de operações interligadas, cuja finalidade é a re-introdução dos materiais recicláveis nos processos produtivos" (PINHEL; ZANIN; MÔNACO, 2011, p. 63). 
Todavia, além de ser um importante instrumento para o gerenciamento eficiente dos resíduos sólidos urbanos e para minimização dos impactos socioambientais, a coleta seletiva pode contribuir efetivamente para a geração de emprego e renda. Quando bem estruturada, pode agregar valor de mercado aos resíduos sólidos e promover a inserção social dos catadores de materiais recicláveis e reutilizáveis (EUZÉBIO, 2018). O autor ainda afirma que, quando a seleção dos materiais é feita de forma adequada, se elevam os ganhos dos "[...] catadores e reduzem os riscos à saúde pública e ao meio ambiente, reduzindo também a extração de recursos naturais na forma de matéria-prima" (EUZÉBIO, 2018, p. 50).

Trata-se poranto de uma atividade econômica rentável ao recuperar matérias-primas que seriam descartadas, e ao gerar possibilidades de emprego e renda, sobretudo para os menos favorecidos. Ademais, contribui para aumentar a vida útil dos aterros sanitários, pois

O mercado de reciclagem se mostra promissor ao país e pode se tornar uma excelente oportunidade para diferentes perfis de empresas, desde aquelas que geram os resíduos e podem lucrar com a venda, passando por aquelas que desenvolvem equipamentos e maquinários para esse fim até as que fazem disso um negócio e reciclam os materiais, efetivamente. A própria lei de resíduos estimula a criação de novos negócios nessa área (SEBRAE/BA, 2017, p. 7).

No ano de 2017, o Brasil produzia 214.868 toneladas por dia de resíduos, o que representava uma geração per capita de 1,035 kg/hab./dia. Desse total, $40 \%$ dos resíduos sólidos urbanos vinham sendo dispostos em aterros controlados e lixões (ABRELPE, 2017), o que demanda a relevância de um sistema de gerenciamento eficiente e eficaz, de modo a desativar os lixões e reduzir a quantidade de resíduos disposta em aterros sanitários. Silva (2013, p. 105) reforça que, “[...] dentre as formas de disposição final dos resíduos sólidos, o aterro sanitário é a mais recomendada". No lixão, ainda utilizado por parte significativa dos municípios brasileiros, mesmo sendo sem o amparo da lei, os resíduos são despejados em valas e cobertos por terra, formando camadas.

De acordo com Silva $(2017$, p. 14), os catadores de materiais recicláveis e reutilizáveis seriam de fundamental importância, pois "realizam um trabalho que consiste em coletar, separar, transportar, acondicionar e, às vezes, beneficiar o material dos resíduos sólidos utilizados que tem valor de mercado e poderá ser vendido para reutilização ou reciclagem". Assim, dá-se, por meio desse trabalho, um novo significado aos resíduos gerados e descartados, considerados inservíveis, transformando-os em novas mercadorias através da coleta seletiva formal ou informal. Segundo Besen (2012), a coleta seletiva pode ser formal, quando há a contratação de organizações coletivas de catadores pelo poder público local, e informal, quando é realizada pelos catadores de forma autônoma e sem qualquer ligação com o poder público.

Silva (2017) acrescenta que a coleta formal de resíduos sólidos, constituída por meio de cooperativas, é um fenômeno relativamente novo e contribui para a valorização profissional dos que atuam nesse segmento, uma vez que os catadores de materiais recicláveis e reutilizáveis foram reconhecidos pela Portaria ${ }^{0} 397$, do Ministério do Trabalho e Emprego (MTE), em 02 de outubro de 2002. Esta providência promoveu a inserção deles 
na Classificação Brasileira de Ocupações (CBO), passando a integrar oficialmente o rol das categorias profissionais do país.

Yoshida, a partir de considerações acerca da Constituição Federal de 1988, pontua que

a participação pública na gestão ambiental é, na verdade, manifestação particularizada do princípio da soberania popular (princípio democrático) em que se assenta a construção do Estado Democrático e Social de Direito Brasileiro (2012, p. 8).

Sendo os municípios os responsáveis pelas ações e metas que objetivam a redução, reutilização, coleta seletiva e reciclagem de materiais, a Política Nacional de Resíduos Sólidos - PNRS (BRASIL, 2010), utiliza-se de alguns instrumentos para que esses entes federativos possam gerir seus resíduos de forma a atender aos princípios estipulados. No sentido de desenvolver uma política de resíduos eficaz, existe a possibilidade da formação de consórcios públicos intermunicipais previstos pela Lei n ${ }^{\circ} 11.107$, de 06 de abril de 2005, a qual objetiva a contratação de consórcio para a realização e otimização de objetivos de interesse comum, o que inclui o gerenciamento de resíduos sólidos (BRASIL, 2005). Dessa forma,

Pretende ampliar a capacidade de gestão das administrações municipais por meio de ganhos de escala e redução de custos no caso de compartilhamento de sistemas de coleta, tratamento e destinação de resíduos sólidos. Quanto aos catadores, possibilita o fortalecimento das redes de organizações e a criação de centrais de estocagem e comercialização regionais (BESEN, 2012, p. 402).

Mesmo com a prática e instalação dos consórcios, é importante frisar que a qualidade das ações que permeiam a gestão e o gerenciamento dos resíduos sólidos depende da cooperação e participação dos segmentos da sociedade: empresa, comunidade e poder público, e só haverá uma efetiva ação de qualidade quando esses segmentos estiverem estruturados e participando ativa e conjuntamente.

Diante do exposto, este artigo objetiva analisar os desafios que dificultam a coleta seletiva de resíduos sólidos nas pequenas cidades. Para este estudo selecionou-se o município de Simão Dias, no Estado de Sergipe que compõe o Consórcio Público de Saneamento Básico do Sul e Centro Sul Sergipano - CONSCENSUL. Esta autarquia intermunicipal com atual sede administrativa na cidade de Indiaroba tem como objetivo integralizar a região e reduzir significativamente os custos para a implantação da PNRS (CONSCENSUL, 2015).

\section{MATERIAIS E MÉTODOS}

Simão Dias localiza-se no extremo oeste do Estado de Sergipe, distante aproximadamente $104 \mathrm{~km}$ da capital do Estado (Fig. 1). A Prefeitura Municipal promove a coleta regular duas vezes por semana, e a coleta seletiva é de responsabilidade exclusiva da Cooperativa de Catadores e Catadoras de Materiais Recicláveis de Simão Dias (COOCAMAR). Outros trabalhadores catam os materiais nas vias públicas de forma autônoma, e uma parcela coleta diretamente no lixão público municipal em condições insalubres e desumanas. 
O serviço que busca a seleção dos materiais pelos catadores é instituído pelo Programa de Coleta Seletiva com inclusão social de catadores, porém a maior parte dos materiais coletados pela prefeitura ainda é disposta no lixão municipal².

Figura 1: Mapa de localização do município de Simão Dias, SE.

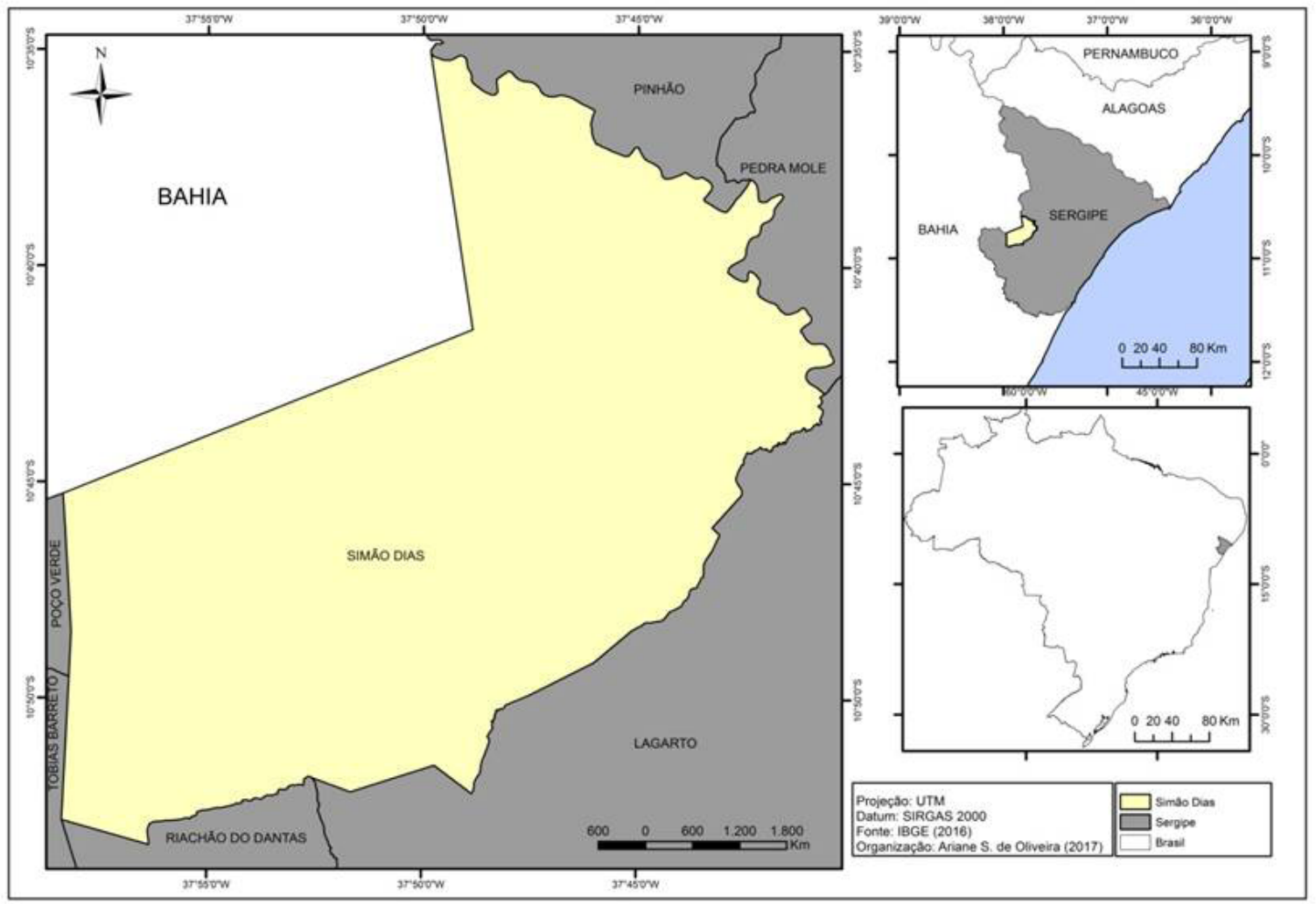

Fonte: IBGE, 2016.

A pesquisa qualitativa envolveu o diagnóstico prévio do local de trabalho dos catadores mediante observação in situ nos locais de coleta - as ruas da cidade e o galpão da cooperativa, com realização de entrevistas. A seguir foi executada uma análise de conteúdo proposta por Bardin, para “... descrição do conteúdo das mensagens" (1977, p. 38).

Através de amostragem intencional, foram entrevistados um representante do poder público e 17 catadores na COOCAMAR, incluindo um representante desta. Foram considerados como catadores aqueles indivíduos que se autodeclararam dessa forma. Atualmente, a cooperativa conta com 38 catadores cadastrados, porém a participação ativa dos membros não é satisfatória, sendo que apenas 20 do total contribuem com os trabalhos desenvolvidos ao menos uma vez a cada quinze dias, dos quais apenas 17 puderam ser contatados durante as visitas realizadas à sede da cooperativa ${ }^{3}$.

2 De acordo com o site Observatório dos lixões, mantido pela Confederação Nacional dos Municípios (CNM), Simão Dias possui um plano municipal de resíduos sólidos, entretanto não houve acesso a este documento para análise. Disponível em: http:/ / www.lixoes.cnm.org.br/

3 A investigação seguiu os preceitos estabelecidos pela Res. no 466/2012, do Ministério da Saúde/Conselho Nacional da Saúde, e foi aprovada pelo Comitê de Ética em pesquisa, por meio da Plataforma Brasil, sob o CAEE no 87658318.6.0000.5546 e o parecer $\mathrm{n}^{\circ} 2.643 .711$. 


\section{A COLETA SELETIVA E O TRABALHO DOS CATADORES COOPERATIVADOS EM SIMÃO DIAS}

A Lei Orgânica Municipal determina, em seu Art. 12, que o município deverá prestar o serviço de limpeza pública de forma direta, por permissão ou concessão. De acordo com a Lei Municipal Complementar n 722/2017, que “Dispõe sobre a nova estrutura organizacional da Prefeitura Municipal de Simão Dias, Estado de Sergipe, a composição das Unidades Administrativas, cria Secretaria, cria e extingue cargos em comissão e dá outras providências", a atual competência para a execução de serviços públicos de limpeza dos logradouros e coleta de lixo é da Secretaria Municipal de Infraestrutura e Urbanismo-SEMIU (Art. 50, IV), sob responsabilidade da Unidade Administrativa de Assessoria de Obras e Manutenção de Serviços Públicos-AOMSP (Art. 50, parágrafo único, III) (SIMÃO DIAS, 2017).

A atual situação de Simão Dias nas ações deliberadas pelo CONSCENSUL mostra que esse município está entre as quatro cidades que mais avançam na região Centro-Sul do Estado de Sergipe com respeito ao número de trabalhadores que compõem a cooperativa, à diminuição do número de catadores que atuavam no lixão público e à parceria existente entre o poder público e a cooperativa local. O que limita o progresso nessa área é a falta de recursos financeiros, pois as ações pleiteadas pelo consórcio exigem do município um valor alto de investimento advindo de recursos próprios, o que se torna, no momento, inviável para a gestão. $\mathrm{O}$ valor da participação financeira mensal entre o município de Simão Dias e o consórcio supracitado é de 0,2 centésimos da cota-parte do Fundo de Participação dos Municípios - FPM - e mais 0,2 centésimos da cota-parte do Imposto sobre Circulação de Mercadorias e Serviços - ICMS - para o custeio das despesas do CONSCENSUL. O trabalho que vem sendo executado por esse consórcio público tem em vista, principalmente, viabilizar o fechamento dos lixões e o fortalecimento das cooperativas de catadores a partir da formação de recicladores (CONSCENSUL, 2015).

Entre as condições impostas pelo Consórcio está a de instrumentalizar e operacionalizar a coleta seletiva nos entes consorciados, como dispõe o artigo $3^{\circ}$, inciso $\mathrm{V}$, da Lei $n^{0}$ 12.305, de 02 de agosto de 2010, através da aquisição de equipamentos para a coleta; da realização de campanhas educativas para a conscientização ambiental; da produção de materiais de divulgação; da publicidade por todas as mídias, com ênfase na correta destinação dos resíduos sólidos; da contratação de empresa para prestação de serviços contábeis; da implementação da política Pró-Catador, em obediência ao Decreto Federal n 7.405 , de 23 de dezembro de 2010, que institui o PNRS.

Na prática, foi observada a ocorrência de apenas uma reunião entre representantes do programa Pró-Catador e os catadores de Simão Dias, no entanto os relatos apontam que já houve capacitações. Porém, é notória a necessidade de uma atenção e uma formação contínua desses profissionais.

Algumas dificuldades encontradas pelo poder público para a implementação eficaz da coleta seletiva foram a dificuldade de obtenção do licenciamento ambiental, o alto custo de implantação de um aterro sanitário, com falta de incentivo financeiro por parte 
do Estado e da União, a distância entre a sede e os locais adequados para disposição e a vulnerabilidade dos catadores.

A atual demanda municipal frente ao consórcio refere-se à instalação de uma unidade de transbordo dentro do perímetro municipal, em busca de um gerenciamento eficaz. Nesse sentido, é relevante o que se frisa o entrevistado E1: "Se realmente for possível a instalação de uma unidade de transbordo dentro do nosso município, visualizo que isso seja muito bom. Aumentaria a arrecadação de Imposto sobre Serviço (ISS) e aumentaria a renda da cooperativa e dos cooperados". Entende-se, com isso, que essa estação permitiria o fechamento do lixão e a abertura de um novo local, onde os resíduos seriam separados por catadores formais, organizados na cooperativa, e as sobras seriam compactadas num caminhão próprio e encaminhadas para um aterro sanitário.

Foi constatado que a coleta seletiva em Simão Dias ocorre há mais de trinta anos, contudo a criação da cooperativa e sua formalização ocorreram apenas em 2014. A cooperativa foi criada com a finalidade de retirar aproximadamente 50 catadores do lixão público municipal e promover a formalização laboral desses profissionais. Os materiais coletados e destinados corretamente contribuiriam para o desenvolvimento socioeconômico dos catadores, propiciando mudanças no estilo de vida, nos hábitos de consumo e nos padrões de comportamento.

Atualmente, apenas os catadores informais coletam materiais recicláveis no lixão; os catadores formais organizados na cooperativa coletam na sede do município, especialmente nas ruas, nos domicílios e no comércio, e transportam esses materiais até o galpão, onde executam a separação, a prensagem, a pesagem e o carregamento dos caminhões para a comercialização. Os catadores organizados recebem benefícios como facilidade e prioridade na marcação de exames e consultas, recebimento de cesta básica mensal e capacitação profissional.

A vinculação entre o poder público municipal e os catadores formais é caracterizada como de companheirismo, e o entrevistado E1 afirma que "No encaminhamento para um aterro, a prefeitura paga por tonelada de resíduos. Se investimos na coleta seletiva, os catadores vão vender os materiais reutilizáveis e vamos pagar menos. Se for feita uma grande separação dos materiais que podem ser reciclados, a quantidade de resíduos que vamos transportar é menor, então o valor que vamos pagar também é muito menor. Por isso é importante que se invista". A Figura 2 apresenta o fluxograma das principais relações estabelecidas entre os catadores de materiais recicláveis e reutilizáveis e a coleta de resíduos no município de Simão Dias. 
Figura 2: Fluxograma da coleta de resíduos sólidos urbanos em Simão Dias.

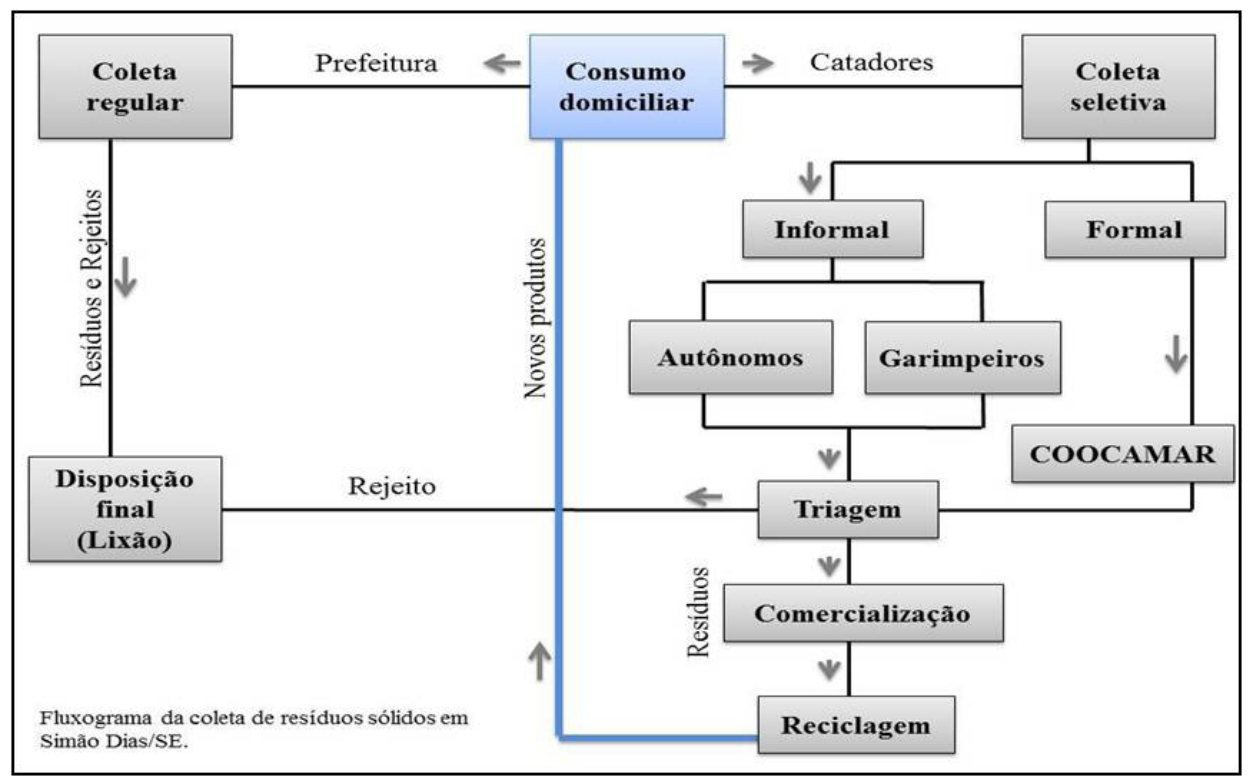

Fonte: as autoras.

\section{A COOCAMAR E O TRABALHO DESENVOLVIDO PELOS CATADORES}

A cooperativa que atua em Simão Dias é composta por pessoas de baixa renda, que não têm emprego fixo e que, através do trabalho desempenhado nessa organização, conseguem atender às necessidades de subsistência de sua família. O trabalho da cooperativa é desenvolvido localmente nas ruas da cidade (Fig. 3) e no galpão na sede da instituição (Fig. 4). É feito de forma coletiva e participativa, pois enquanto alguns catadores fazem a triagem, outros prensam, pesam e carregam os caminhões.

Figura 3: Catador cooperativado atuando nas vias públicas da cidade de Simão Dias.

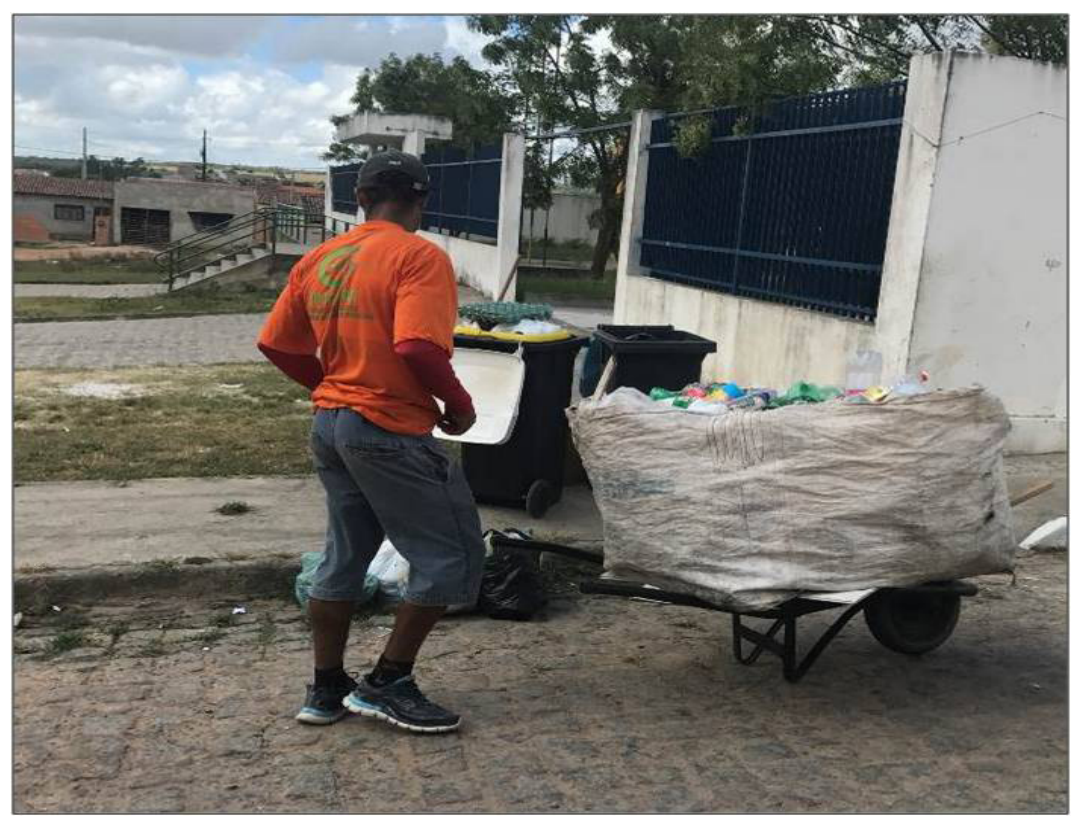

Fonte: OLIVEIRA, 2018. 
A quantidade média de materiais conseguidos pela cooperativa varia de 300 a 500 $\mathrm{kg} /$ semanal. Os materiais são provenientes da parceria existente com algumas empresas da cidade, da coleta nas vias, além das doações por parte da população. Os principais materiais coletados pelos catadores são papel/papelão, vidro, cobre, alumínio, plástico, ferro e metal. Quanto ao rendimento médio mensal familiar do catador, 58,8\% dos entrevistados afirmaram receber menos de um salário mínimo.

Figura 4: Catadores realizando a triagem de materiais recicláveis na sede da COOCAMAR.

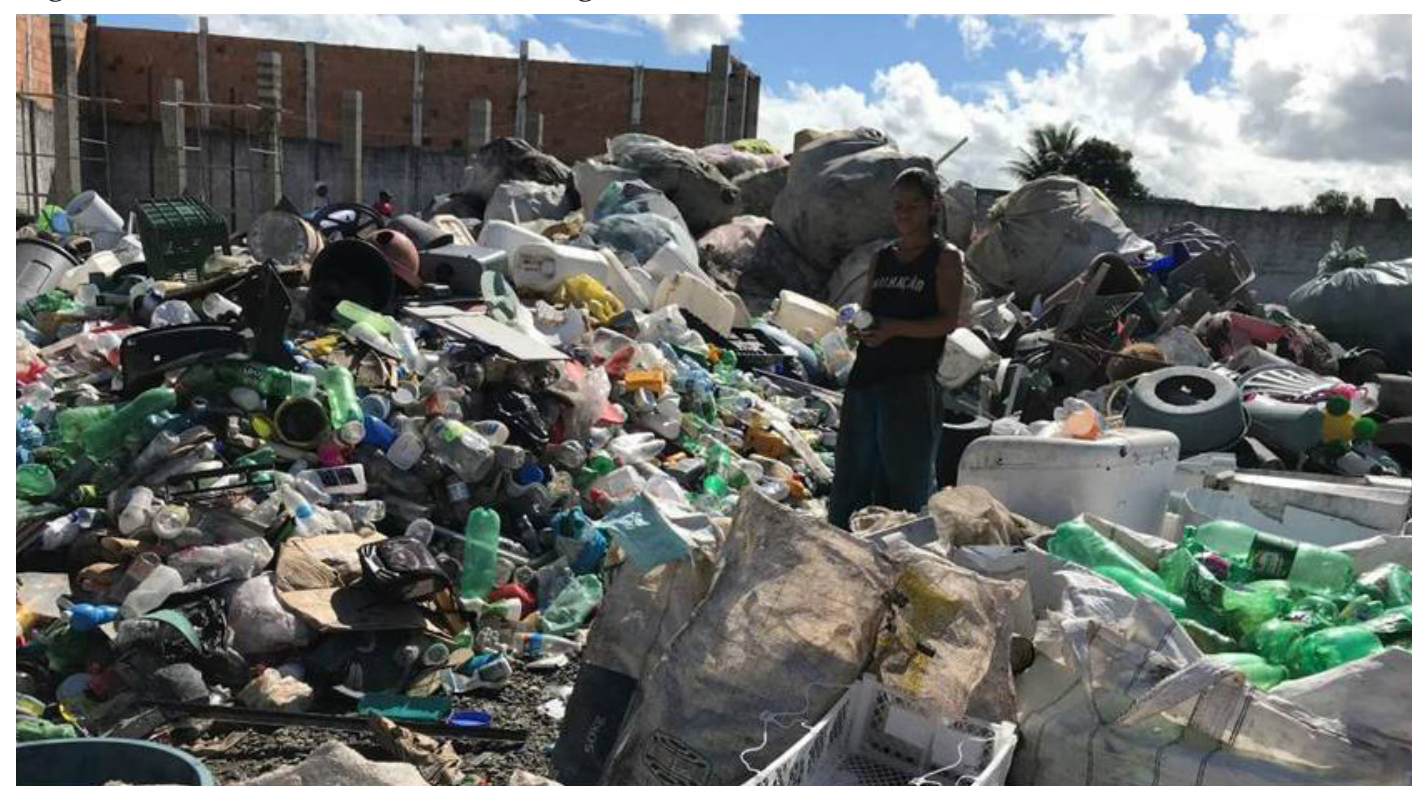

Fonte: OLIVEIRA, 2018.

A cooperativa não admite que seus membros coletem no lixão público. No entanto, durante as entrevistas, foi possível constatar que a cooperativa também compra materiais de catadores informais, quando estes não conseguem vender a outros. Isso porque

As cooperativas de catadores também possuem um papel essencial no desenvolvimento de alternativas de inclusão dos catadores(as) que fazem a opção de se manter desvinculados de associações ou cooperativas, mas que não poderão ser excluídos da coleta seletiva. As cooperativas passam a ter papel de articulação nos locais e se tornam fontes de alternativa para inclusão do material coletado por esses catadores independentes, garantindo que não haja depreciação e exploração do trabalho desses (PINTO; AZEVEDO; BATISTA, 2018, p. 21).

A pesquisa evidenciou que o uso de Equipamentos de Proteção Individuais (EPIs) não faz parte da rotina diária desses profissionais, contudo os catadores organizados formalmente por meio da cooperativa, utilizam ao menos um dos equipamentos de segurança básicos. Outro ponto relevante que deve ser destacado é a não visualização de crianças trabalhando na coleta seletiva do município.

O reflexo da precariedade da atividade desenvolvida pode ser evidenciado por meio do contato que esses trabalhadores podem ter com materiais nocivos, em face de riscos 
físicos, químicos e biológicos, mas também pela exposição a situações de ameaça e ou preconceito. Essa preocupação é reforçada pelo relato do catador $\mathrm{C} 35$, quando afirma que "Teve um dia que eu ia passando na rua e uma mulher me ofereceu um pedaço de bolo, e eu aceitei. Quando ela me deu, o bolo já tava comido, era o resto. Não quis comer. Ela achou que eu era um bicho? Mas também encontra gente boa, as vezes me dão café e pão". Nesse contexto, entende-se que os catadores podem sofrer, além de desgaste físico, um esgotamento emocional devido às situações a que estão expostos. Outro fator que também contribui para a precarização dessa atividade é a falta de infraestrutura dos locais em que os trabalhos são realizados, o que necessitaria de mais investimento para, consequentemente, proporcionar mais dignidade e qualidade de vida e segurança aos catadores.

Ademais, há deficiências no tocante à autossustentabilidade da cooperativa. Uma importante reflexão diante dos problemas elencados pelos catadores que trabalham na cooperativa diz respeito aos desafios que a circundam e seus associados, uma vez que os catadores, como pontua Paravidino, "encontram-se inseridos numa vulnerabilidade intrínseca ao grupo, por não entenderem este tipo de organização social como um importante instrumento capaz de conduzi-los a melhores condições de trabalho e vida" (2018, p. 136). Para o catador e representante da instituição, a maior vantagem em trabalhar de forma legal se constitui principalmente nos benefícios que a cooperativa dispõe para seus membros e nas parcerias que firmam com órgãos públicos. Assim, "Se algum cooperado estiver doente, a gente faz de um tudo para ajudar no que a gente pode" (E2).

No tocante aos desafios enfrentados pela cooperativa, destacam-se a assiduidade, a pontualidade e a integração entre os cooperados, a inexistência de um local próprio e adequado para o trabalho, a falta de equipamentos como esteira, fardamentos como calça, camisa, bonés, com entregas de no máximo a cada seis meses, a necessidade de um carro maior para o transporte dos materiais e a falta de divulgação dos trabalhos desenvolvidos. Isto posto, considera-se que, se houvesse uma maior participação social, a arrecadação de material aumentaria e, consequentemente, os ganhos entre os cooperados também.

A COOCAMAR considera de fundamental importância o incentivo financeiro recebido pela prefeitura e reconhece a magnitude da contribuição social no desenvolvimento da coleta seletiva municipal. A parceria entre a cooperativa e o poder público apresenta certa fragilidade, porém é indispensável para o andamento dos trabalhos, bem como para a estruturação e o funcionamento da entidade. A coparticipação entre o executivo municipal e a cooperativa na promoção da coleta seletiva aponta para o fortalecimento dos catadores enquanto categoria profissional e para a formalização laboral, através de cursos, palestras e reuniões promovidos pelo SEBRAE e pelo CONSCENSUL.

Os benefícios oriundos da coleta seletiva são indiscutíveis e de grande relevância social, todavia a organização em cooperativa contorna situações adversas, a exemplo dos problemas elencados anteriormente. Essa mesma conclusão foi alcançada por Moreira et al., quando expõem que:

Vários estudos sobre as condições de trabalho dos catadores organizados em cooperativas e associações ilustram a precariedade do ambiente e a vulnerabilidade dos 
trabalhadores às inúmeras doenças relacionadas ao trabalho. São problemas comumente encontrados em CTs: periculosidade dos materiais manipulados; indisponibilidade de tecnologias seguras e facilitadoras; déficit de treinamento; baixa adesão ao uso de equipamentos de proteção; acúmulo de rejeitos; ambientes insalubres; presença de animais sinantrópicos, acidentes, adoecimento físico e mental. Também são frequentes dores musculoesqueléticas e problemas respiratórios, gastrintestinais, auditivos e emocionais (2018, p. 112).

Assim, infere-se que, mesmo com alguns benefícios aparentes, a organização em cooperativa ainda é precária. A cooperativa é encarada por muitos catadores, sobretudo por aqueles que se negam a participar e contribuir para o seu desenvolvimento e fortalecimento, como um agente externo e não como uma organização formada e gerida pelos próprios catadores.

\section{CONSIDERAÇÕES FINAIS}

A coleta seletiva vem se consolidando com o decorrer dos anos e traz ganhos, de forma assertiva, para quem dela participa. A formalização da coleta seletiva no município de Simão Dias ainda não atingiu todo o potencial esperadoa, primeiro porque o trabalho desenvolvido ainda é restrito à zona urbana, e segundo porque os catadores demonstram deficiencias em impulsionar o crescimento da cooperativa, em parte devido à baixa participação social na separação e destinação correta dos resíduos gerados.

O principal empecilho para uma maior estruturação e fortalecimento da cooperativa local, na visão do poder público municipal, é a questão financeira, visto que é requerido um alto investimento com verbas próprias e não existe uma política articulada e de incentivo financeiro por parte dos demais entes federativos. Com isso, a prefeitura local fica impossibilitada de investir um valor alto para favorecer apenas a esse setor.

Os catadores de materiais recicláveis e reutilizáveis se beneficiam, pois, em sua maioria, são pessoas que não conseguem adentrar o mercado formal de trabalho e que, por meio da coleta de resíduos passíveis de reciclagem, conseguem atribuir um valor de mercado aos materiais coletados, mantendo assim a subsistência da família. Contudo, mesmo com alguns benefícios aparentes, a organização em cooperativa ainda é precária. Há carências físicas de condições mínimas de trabalho, faltam materiais de proteção individual e equipamentos como esteiras, além de veículos, recipientes de armazenamento de materiais, galpão próprio e adequado, entre outros. Além disso, mesmo com a existência de uma cooperativa, ainda atuam em Simão Dias catadores informais, sobretudo coletando materiais no lixão, um local inóspito e insalubre. É importante destacar que a opção de formalização existe, porém sua adesão é voluntária e intrínseca a cada trabalhador. A não adesão ocorre por diversos motivos, entre eles a não aceitação do trabalho em conjunto, a não adequação às regras impostas, como também a decisão de não se assumir como catador, preferindo continuar no anonimato. 
A formalização dos catadores busca organizar o trabalho de forma democrática através do engajamento coletivo, da capacitação dos envolvidos e da autogestão da cooperativa, numa perspectiva emancipadora e equitativa. Embora o poder público tenha parceria com a cooperativa, não há incentivos financeiros nem educativos para a sociedade participar e contribuir com a coleta seletiva municipal. Inclusive não existe legislação no âmbito municipal que incentive a doação de materiais recicláveis à cooperativa pelo comércio, pelas escolas e/ ou pelas indústrias. Por outro lado, se tal lei existisse, os cooperados teriam dificuldades no sentido de realizar a coleta numa demanda maior devido à escassez de veículos e de equipamentos necessários.

Visto que a coleta seletiva é de particular relevância para o gerenciamento eficiente e eficaz de resíduos sólidos, é fundamental desenvolver projetos de educação ambiental para sensibilizar e promover a participação do poder público e da comunidade, a fim de atender aos anseios dos catadores e promover sua inserção social e a sustentabilidade da cooperativa.

\section{REFERENCIAS}

ABRELPE. Associação Brasileira de Empresas de Limpeza Pública e Resíduos Especiais. Panorama dos Resíduos Sólidos no Brasil - 2017. Edição Especial 15 anos. São Paulo, 2017.

BARDIN, Laurence. Análise de conteúdo. Lisboa: Edições 70, 1977.

BESEN, Gina Rizpah. A questão da coleta seletiva formal. In: PHILIPPI JUNIOR, Arlindo (Coord.). Política Nacional, Gestão e Gerenciamento de Resíduos Sólidos. Barueri: Manole, 2012. p. 389-414.

BRASIL. Lei n ${ }^{0} 11.107$, de 06 de abril de 2005. Dispõe sobre normas gerais de contratação de consórcios públicos e dá outras providências. 2005. Disponível em: http://www.planalto.gov.br/ccivil_03/_ Ato2004-2006/2005/Lei/L11107.htm. Acesso em: 01 nov. 2017.

Lei $n^{\circ} 12.305$, de 02 de agosto de 2010. Institui a Política Nacional de Resíduos Sólidos. Disponível em: http://www.planalto.gov.br/ccivil_03/_ato2007-2010/2010/Lei/112305.htm. Acesso em: 27 maio 2017.

CAIXETA, Dalma M. Geração de energia elétrica a partir da incineração de lixo urbano: o caso de Campo Grande/MS. Brasília, 2005. Monografia (Especialização em Direito Ambiental e Desenvolvimento Sustentável) - Universidade de Brasília, UnB. Disponível em: www.mpf.mp.br/atuacao-tematica/ccr4/ dados-da-atuacao/documentos/trabalhos-cientificos/dissertacao_dalma.pdf Acesso em: 04 set. 2019.

CONSCENSUL - Consórcio Público de Saneamento Básico do Sul e Centro Sul de Sergipe. Estatuto. 2015. Disponível em: https://www.conscensul.com.br/css/documentos/doc_conscensul/Estatuto $\% 20$ do $\% 20$ Conscensul.pdf Acesso em: 10 nov. 2018.

CORTEZ, Ana Tereza C. Coleta seletiva e reciclagem de resíduos sólidos urbanos. In: CAMPOS, J. O.; BRAGA, Roberto; CARVALHO, Pompeu F. de (Orgs). Manejo de resíduos sólidos: pressuposto para a gestão ambiental. Rio Claro, DEPLAN / IGCE /UNESP, 2002. p. 99-109.

EUZÉBIO, Lucinei Aparecido. Coleta Seletiva: desafios na implantação e suas possibilidades por meio da educação ambiental. Presidente Prudente, 2018. Dissertação (Mestrado em Geografia) - Universidade Estadual Paulista, UNESP.

FROTA, Antonio Jackson A. et al. Implantação de um sistema de coleta seletiva: aspectos legais e de sustentabilidade. Revista de Gestão e Sustentabilidade Ambiental, v. 4, n. 1, p. 129-155, abr./set. 2015. Disponível em: http://www.portaldeperiodicos.unisul.br/index.php/gestao_ambiental/article/ view/2312 Acesso em: 13 nov. 2018. 
MONTEIRO, José Henrique et al. Manual de Gerenciamento integrado de resíduos sólidos. Rio de Janeiro: IBAM, 2001.

MOREIRA, Ana Maria Maniero et al. Riscos à saúde do catador de materiais recicláveis, medidas preventivas e assistência à saúde. In: SOUZA, Roseane Maria Garcia Lopes de (Org.). Saneamento ambiental e saúde do catador de material reciclável. São Paulo: Limiar, 2018. p. 111-128.

PARAVIDINO, Gislaine Souza Magdalena. A questão socioambiental dos resíduos sólidos urbanos no município de Paraíba do Sul/RJ e as interfaces com a Política Nacional dos Resíduos Sólidos. Juiz de Fora, 2018, Dissertação (Mestrado em Geografia) - Universidade Federal de Juiz de Fora, UFJF.

PINHEL, Julio Ruffin; ZANIN, Maria; MÔNACO, Graziela Del. Catador de Resíduos Recicláveis: um perfil profissional em construção. In: ZANIN, Maria; GUTIERREZ, Rafaela Francisconi (Orgs.). Cooperativas de Catadores: reflexos sobre práticas. São Carlos: Claraluz, 2011. p. 53-101.

PINTO, Ana Luísa Ferreira; AZEVEDO, Davi Quintanilha Failde de; BATISTA, Gislaine Menezes. Gestão, legislações e competências: o manejo de resíduos e o cooperativismo. In: SOUZA, Roseane Maria Garcia Lopes de (Org.). Saneamento ambiental e saúde do catador de material reciclável. São Paulo: Limiar, 2018. p. 10-28.

SCACABAROSSI, Haroldo; PÉRICO, Eduardo. Perspectivas e desafios da coleta seletiva na cidade de Boa Vista - RR, no contexto da Política Nacional de Resíduos Sólidos, Lei Federal n ${ }^{0}$ 12.305/2010. Rev. Geografia, v. 23, n. 2, p. 49-69, jul./dez., 2014.

SEBRAE/BA. Comércio e serviços: reciclagem de resíduos. 2017. Disponível em: https://m.sebrae.com. br/Sebrae/Portal\%20Sebrae/UFs/BA/Anexos/Reciclagem\%20de\%20resíduos\%20na\%20Bahia.pdf Acesso em: 10 nov. 2018.

SILVA, Maria do Socorro Ferreira da. Resíduos Sólidos Domiciliares e os múltiplos desafios ao seu gerenciamento. São Cristóvão: Ed. UFS, 2013.

SILVA, Sandro Pereira. A organização coletiva de catadores de material reciclável no Brasil: dilemas e potencialidades sob a ótica da economia solidária. Brasília: IPEA, 2017.

SIMÃO DIAS. Lei Municipal Complementar $n^{\circ}$ 722/2017. Dispõe sobre a nova Estrutura Organizacional da Prefeitura Municipal de Simão Dias, Estado de Sergipe, a composição das Unidades Administrativas, cria Secretaria, cria e extingue cargos em comissão e dá outras providências.

YOSHIDA, Consuelo. Competência e as diretrizes da PNRS: conflitos e critérios de harmonização entre as demais legislações e normas. In: PHILIPPI JUNIOR., Arlindo (Coord.). Política Nacional, Gestão e Gerenciamento de Resíduos Sólidos. Barueri: Manole, 2012. p. 3-38.

Data da submissão: 06/ mar./ 2019

Data de aceite: 28/ ago. / 2019 